\title{
Local Willingness-to-Pay Estimates for the Remediation of the Sydney Tar Ponds in Nova Scotia
}

Ida Ferrara, Economics, Atkinson, York University, Toronto, Canada.

Stephen McComb, Chicago Climate Exchange, Chicago, IL, USA.

Paul Missios, Department of Economics, Ryerson University, Toronto, Canada

\begin{abstract}
The Sydney Tar Ponds and Coke Ovens site in Nova Scotia, Canada, is among the most toxic hazardous waste sites in North America. This study presents hedonic estimates of the willingness-to-pay for remediation of the site using housing sales data from urban Sydney. Negative impacts are estimated with a maximum likelihood spatial autoregressive model of property values. Premiums on homes farther from the site are found to be substantial, and, when aggregated into a community willingness-to-pay measure ( $\$ 169.2$ million), cover a large proportion of the estimated remediation costs.
\end{abstract}




\section{Introduction}

The Sydney Tar Ponds in Nova Scotia, Canada, is one of the most toxic hazardous waste sites in North America. At the location of what was once the largest steel producer in North America, ${ }^{1}$ existing surface water and sediment at the Tar Ponds site (referring primarily to the North and South Tar Ponds and the nearby Coke Ovens area) now contain a wide variety of hazardous pollutants in substantial quantities. Derelict industrial sites such as this one have previously been shown to pose significant health risks and economic impacts to residents living in the area, particularly those with dwellings adjacent to the site. Recently, efforts have been made to agree upon a cleanup plan, and the federal and provincial governments have indicated some willingness to share remediation costs. ${ }^{2}$ The costs of such a clean-up, however, are quite substantial.

Two issues arise from the potential remediation. The first concerns the total benefits to individuals and households, and whether those benefits justify the costs of the remediation, particularly when there are several remediation options available with significantly differing costs. The second concerns the distribution of benefits across individuals, as the clean-up has more direct impacts on individuals living near the site than on those living farther away. This study in part addresses both issues. Hedonic prices for proximity to the site are estimated to approximate the willingness-to-pay for remediation of local residents. These willingness-to-pay estimates are then aggregated and compared to projected remediation costs (in present value) to determine what proportion of remediation costs would be offset by local benefits. While there may be 
benefits to others in the region and possibly to individuals farther away, this study only uses local property sales data, and accordingly no attempt is made to estimate the nonlocal benefits from remediation.

Most of the studies on the impacts of hazardous waste sites are concerned with locations within the United States. These studies, including Adler et al. (1982), Smith and Desvouges (1986), Michaels and Smith (1990), Kohlhase (1991), Ketkar (1992), Kiel (1995), Gayer et al. (2000), Kiel and Zabel (2001), and Ihlanfeldt and Taylor (2004), typically estimate the price-distance gradient with the common finding that toxic sites reduce property values by significant amounts $(\$ 9,468$ per mile in Adler et al., but more frequently $\$ 1,500-4,000$ per mile). A few of these studies use the price-distance estimates to obtain total willingness-to-pay estimates for the communities in a costbenefits analysis (e.g., Ketkar, Kiel and Zabel, and Gayer et al.). Not all studies, however, find positive net benefits of remediation; Gayer et al., for example, conclude that the upper bound of the benefits from cleaning up a site in Michigan is $\$ 10.1$ million, well below the cleaning-up costs of $\$ 56.8$ million.

Past works use various specifications of the housing price equation, particularly linear, log-linear, semi-log, and Box-Cox. ${ }^{3}$ More recent hedonic studies, many unrelated to hazardous waste sites (but including Ihlanfeldt and Taylor on the impacts of hazardous sites on residential high-rise, industrial, and commercial properties), employ spatial autoregressive models. Hedonic models of property values are potentially subject to spatial autocorrelation as properties located in the same area tend to have similar 
unobservable characteristics (Bell and Bockstael, 2000). Spatial models are shown to provide significantly more efficient estimates than other methods.

This paper presents one of the few hedonic estimations of the impact of a major hazardous waste site performed outside of the United States, and the only such analysis known to the authors conducted for a hazardous waste site in Canada. In addition to presenting the results of an OLS estimation, this paper presents the results of a maximum likelihood spatial autocorrelation model. While the two estimations yield similar results, there are important differences between the two options. To examine the distribution of potential benefits of remediation, a non-linear price-proximity gradient is posited, and predicted values of properties at different locations calculated. Finally, an aggregate value for community willingness-to-pay is computed using the results of the spatial regression and compared to cost estimates.

The next section provides a brief outline of the nature of the contamination at the site, illustrating the various pollutants and their sources. This is followed by a description of the framework employed in the literature and in this study, including a summary of spatial modelling. Section 4 contains a discussion of the data utilized and the model estimated, as well as expectations regarding the impacts of the independent variables. Section 5 presents the empirical results and a discussion of the implications for both the distribution of benefits and the total benefits from remediation.

\section{Contamination at the Site}


The former steel plant is geographically located in the centre of Sydney, ${ }^{4}$ on Cape Breton Island in the north of Nova Scotia. The South Pond is fed with water by the Muggah Creek through the Coke Oven Brook Connector, and drains into the North Pond. The North Pond opens up to Sydney Harbour to the northwest and is bordered by the steel plant site to the north and east. The Coke Ovens area once contained a variety of structures, including by-products, coal tar processing, and silica brick plants. Except for the dumping of slag waste, no activities took place at the Tar Ponds. Nonetheless, the Tar Ponds were the recipients of contaminated water via surface drainage, groundwater infiltration from the Coke Ovens site and the former steel plant, as well as sanitary sewage outfalls from the community. Coal tar, sediment contaminated with hydrocarbons, polycyclic aromatic hydrocarbons (PAHs), heavy metals, and polychlorinated biphenyls (PCBs) subsequently accumulated in the Tar Ponds. The hazardous waste site and surrounding areas are illustrated in Figure 1.

[Insert Figure 1 here]

Figure 1. Map of the waste site and surrounding area. Source: Public Works and Services Canada, 2005. http:///www.pwgsc.gc.ca/text/articles/2005/02/2005-02-tarponds-e.html

The primary source of waste chemicals (including coal tar, ammonia, sulphur, and light oils) was the processing of coal into coke. In the early years of production at the steel 
plant, by-product chemicals were collected and refined, reused and/or sold as final chemicals. This process was fairly successful at extracting chemicals that had economic value either within the plant or for the resale market. However, when the prices for byproduct chemicals fell, the products were allowed to accumulate in unsecured areas onsite or were disposed of directly onto the soil or into watercourses (CBCL/ENSR, 2003a).

Several contaminants have been identified at the site, including coal tar in subsurface soils and in stream sediments, total petroleum hydrocarbon (TPH) compounds in the sediment of the Coke Oven Brook as well as in surface and subsurface soils at the site, PAHs in the sediment of the Coke Oven Brook as well as in surface and subsurface soils and groundwater, and groundwater contamination by 2,4-dimethylphenol and pyridine (CBCL/ENSR, 2003a). It is estimated that these contaminants exist in 280,000 $\mathrm{m}^{3}$ of soil. The Tar Ponds became the natural collection point for many of the contaminants entrained in sediments from surface runoffs, streams, and outfalls. Other sources of contamination in the Tar Ponds include slag, which was used as a fill material in large volumes (CBCL/CRA, 1999), ${ }^{5}$ twenty dissolved metals in the water at the North and South Ponds, TPH and volatile organic compounds (VOCs) in both North and South Pond sediment and water, and four metals, PCBs, and PAHs in both North and South Pond sediment.

It is estimated that the Tar Ponds contain $550,000 \mathrm{~m}^{3}$ of contaminated sediment, an estimated $45,000 \mathrm{~m}^{3}$ of which is expected to contain PCBs (CBCL/ENSR, 2003b). 
Complicating potential clean-up activities, sanitary sewage continues to flow untreated into the South Tar Pond. The Coke Ovens site continues to contribute significant amounts of contaminants to the Tar Ponds, via various pathways (see Table 1). Further investigation by CBCL/ENSR (2003b) indicates that the South Tar Pond is a net receptor of contaminants despite its outlet into the North Pond.

\begin{tabular}{|l|c|c|c|c|}
\hline Type & Loading (kg/yr) & $\begin{array}{c}\text { \% from surface } \\
\text { water }\end{array}$ & $\begin{array}{c}\text { \% from } \\
\text { groundwater }\end{array}$ & $\begin{array}{c}\text { \% from sewer } \\
\text { outfall }\end{array}$ \\
\hline TPH & 25,709 & 68 & 5 & 27 \\
\hline Metals & 1,942 & 56 & 28 & 16 \\
\hline PAHs & 310 & 23 & 75 & 2 \\
\hline
\end{tabular}

Table 1. Contaminant Loading to Tar Ponds. Source: JDAC (2002).

The community's concerns that toxins present at the site were causing considerable health problems precipitated a human health risk assessment study. In 2001, research findings concluded that Sydney was as safe a place to live as any other urban area in the province. ${ }^{6}$ In March 2002, human health risk assessments conducted by the government concluded that living close to the site was safe. Nonetheless, by the late summer of 2002, some properties close to the site were remediated at the government's expense. In February 2003, the federal government announced a significant funding initiative to clean contaminated sites across the country, and open debate ensued regarding Sydney's share. In March of 2003, a human health risk assessment 
concluded that residents of Whitney Pier and Ashby, the two neighbourhoods that are closest to the site, had a greater risk of cancer than the national average, and, two months later, Sydney residents in participation with the Joint Action Group chose to recommend to the government clean-up Option 3 for the Tar Ponds and Option 4 for the Coke Ovens at a combined cost of $\$ 432.8$ million over 11 years. ${ }^{7}$

\section{Framework of Evaluation}

The belief that property values are affected by the presence of hazardous materials is not new in the literature. The earliest work on the linkages between property values and environmental disamenities, Harrison and Rubinfeld (1978), is concerned with air quality and attempts to infer the marginal value of clean air from housing prices. More recent studies consider the effects of water quality (Leggett and Bockstael, 2000; Mendelsohn et al., 1992; Poor et al., 2001), highway noise (Palmquist, 1992), rainfall (Englin, 1996), and proximity to Superfund sites (Ketkar, 1992; Kiel, 1995; Kohlhase, 1991), to hog operations (Palmquist et al., 1997), to the transportation of nuclear waste (Gawande and Jenkins-Smith, 2001), and to incinerators (Kiel and McClain, 1995).

As property values are influenced by the characteristics of the property and neighbourhood, hedonic pricing models are widely used in measuring the effects of environmental disamenities on property values, although one of the earliest applications of hedonic analysis to the housing market (Rosen, 1974) does not include 
environmental conditions. According to the hedonic pricing method, the price of any good is assumed to relate to the stream of benefits derived from the characteristics of the good (Lancaster, 1966). In the context of the housing market, the hedonic pricing method relates the price of a house to the property characteristics and locational attributes, including environmental hazards.

Hedonic house price models that estimate location-specific premiums may however suffer from spatially correlated error problems for two primary reasons. The first source of autocorrelation in the error term is due to improper spatial modelling or spatial heterogeneity of the market (Anselin, 1988; Basu and Thibodeau, 1998; Orford, 1999); models that treat the entire data set as equal do not realistically represent the spatially distinct sub-markets or neighbourhoods. The second cause of autocorrelation in the error term is due to locational homogeneity in housing attributes; prices of nearby homes are similar given that they share neighbourhood and structural characteristics and the value of some homes has an externality effect on nearby homes (Can, 1990; Orford, 1999). In the presence of spatial autocorrelation, the OLS estimates of the parameters of the model are inefficient and most likely inconsistent (spatial correlation has the same effects as serial correlation in time series data). Given the policy relevance of the study, not accounting for spatial correlation may result in inaccurate recommendations.

Just to cite a couple of examples about the importance of accounting for spatial correlation, a study by Pace and Gilley (1997) finds that, by applying a spatial 
autocorrelation model to data previously examined with OLS by Harrison and Rubinfeld (1978), the sum of squared errors is reduced by $44 \%$. Another study by Dubin (1988) finds that the mean squared error (MSE) of prediction is $21 \%$ lower using ML over OLS since the ML method uses information from other observations in estimating the coefficients and calculating the predicted values. Even when Dubin includes neighbourhood variables that greatly improve the OLS predicted values, the reduction in the MSE of prediction using ML over OLS, although lower, is still substantial at $11 \%$.

The hedonic methodology generally requires two steps in the estimation: in the first step, the hedonic price schedule is estimated; in the second step, demand or bid functions are obtained. The need for the second step arises as the hedonic price schedule derived in the first step represents an equilibrium price schedule and does not reveal information about individual behaviour. Because of the theoretical and empirical complexities in the second step, ${ }^{8}$ many empirical studies employing the hedonic methodology only consider the first stage of the estimation. This approach is particularly suitable when the externalities under consideration are localized (Palmquist, 1992; Hunt et al., 2005). A localized externality affects only those in proximity to the externality; examples of localized externalities include leaking underground storage tanks, highway noise, and some locally undesirable land uses such as landfills for solid waste. The effects of hazardous waste sites, particularly those near residential areas, are also localized; Kohlhase (1991) finds in fact that housing prices are only affected within 6.2 miles of the sites and that most of the effects take place within a smaller radius. With a localized externality, it is sufficient to estimate the hedonic equation for a relatively 
homogeneous neighbourhood as the equilibrium hedonic price schedule is unchanged by the externality (Palmquist, 1992).

\section{Data and Method}

This study employs housing transaction data obtained from the Nova Scotia Association of Realtors (NSAR) and spatial map information provided by Conestoga Rovers and Associates as project managers for the Tar Ponds and Coke Ovens Clean-up Project. Real estate transaction data, from the NSAR's multiple listing system (MLS), are available for the period of January 1998 through April 2003. Sale prices are adjusted using the new housing price index from Statistics Canada to 1997 dollars. As only postal code information is available for each sale, the location of homes is generalized to the centre point of the postal code range. Each house location is assigned geographic coordinates by a process of geo-coding based on the geographical information system ArcGIS, matching postal codes from the MLS data to the streets file provided in the geographical data set. Distances between homes and the Tar Pond and Coke Ovens site and the Sydney downtown core (the Cape Breton Regional Municipality building), also referred to as the Central Business District (CBD) in the paper, are then calculated. Due to missing variables, particularly postal codes or addresses necessary for the spatial estimation, some sales observations are dropped. There are 390 observations pertaining to residential single-family dwellings in the final data set. 
Table 2 presents summary statistics for the data used in the hedonic regression. The closest home to the Tar Pond site is 76 metres away, while the house furthest away is just over 5.9 kilometres from the site. Over $64 \%$ of the houses in the sample are between 500 metres and 2 kilometres from the site. Fewer than $4 \%$ of the homes in the sample are more than 3 kilometres from the site.

\begin{tabular}{|l|l|c|c|c|}
\hline Variable & Description & Mean & Std. Dev. & Min/Max \\
\hline SALE_PRICE & Sales price in 1997 dollars & 58802.37 & 27198.16 & $4642.5 / 211907$ \\
\hline AGE & Age of the home in years & 46.43 & 22.37 & $2 / 125$ \\
\hline LOT_SIZE & Size of the property in square feet & 6853.97 & 5071.95 & $1680 / 45000$ \\
\hline TLA & Total living area of the home in & 1469.24 & 543.63 & $480 / 4400$ \\
\hline NBR_BATH & square feet & & & \\
\hline NBR_BED & Number of bathrooms in the home & 1.39 & 0.58 & $1 / 4$ \\
\hline FIREPLACE & Indicator for a fireplace, 1=yes 0=no & 0.39 & 0.49 & $0 / 1$ \\
\hline GARAGE & Indicator for a garage or shed, 1=yes & 0.44 & 0.49 & $0 / 1$ \\
& $0=$ no & & & \\
\hline TWO_STOREY & Indicator for two storey style, 1=yes & 0.35 & 0.48 & 0.81 \\
\hline D=no & The minimum distance to the CBD in & 1925.74 & 752.88 & $166 / 5391$ \\
\hline D_CBD & metres & & & \\
\hline & The minimum distance to the site in & 1424.13 & 858.80 & $76 / 5917$ \\
\hline
\end{tabular}




\begin{tabular}{|l|l|l|l|l|}
\hline & metres & & & \\
\hline LN_D_SITE & Natural logarithm of D_SITE & 7.05 & 0.71 & $4.33 / 8.69$ \\
\hline
\end{tabular}

Table 2. Dependent and independent variables and descriptive statistics.

Of the independent variables available, several are related to the physical characteristics of the house including age (AGE), total living area (TLA), the number of bathrooms (NBR_BATH), the number of bedrooms (NBER_BED), the presence of a fireplace (FIREPLACE), the presence of a garage or shed (GARAGE), and the style of house (TWO_STOREY). Neighbourhood characteristics include the lot size (LOT_SIZE), the distance to the Tar Ponds (D_SITE), and the distance to downtown Sydney (D_CBD). ${ }^{9}$

Past findings and theory suggest well-defined expectations on the signs of most coefficients. As potential buyers discount older homes, AGE is expected to have a negative impact on house prices (SALE_PRICE). The influence of LOT_SIZE is expected to be positive given the premium individuals place on features such as larger lawns and space between homes, and lot size is often viewed as a proxy for neighbourhood desirability. TLA is expected to have a positive impact on prices as larger total living area reflects larger and more luxurious homes. The number of bathrooms (NBR_BATH) in a home is expected to have a positive effect as homes with ensuite bathrooms and powder rooms are more desirable and command price premiums. The number of bedrooms (NBR_BED) in a home is also expected to have a 
positive influence (although some studies in the literature find the opposite relationship). Individuals tend to value amenities such as fireplaces and garages (or sheds); accordingly, the coefficients of the binary FIREPLACE and GARAGE variables are expected to be positive. No expectation is placed on the sign of the coefficient on the TWO_STOREY variable. The coefficient on the distance to the city centre (D_CBD) is expected to be negative.

The variable most relevant to this study is the distance to the Tar Ponds and Coke Ovens site. Homes closest to the site can be expected to bear the greatest externalities from the toxicity, and therefore should bear the largest negative impact on property value. As the distance from the site increases, the negative externalities diminish and property values should increase. As in other recent studies (e.g., Mahan et al, 2000, and Brasington and Hite, 2005), the price-distance gradient is assumed to be nonlinear, with properties closest to the site experiencing the highest marginal value changes, so the natural logarithm of the distance (LN_D_SITE) is used, with the expectation that the coefficient is positive if individuals are willing to pay to live farther away from the hazard.

\section{Results}

Initial regressions are performed using OLS (Model 1). Various tests common in property price analyses are then employed for spatial autocorrelation and 
heteroskedasticity. Both the spatial lag and the spatial error models are considered to account for prices being partially set in response to prices charged at neighbouring sites (in the former) and for mis-specification errors due to omission or mis-specification of independent variables (in the latter) $;{ }^{10}$ in both cases, the spatial parameter is found to be significantly different from zero based upon the Lagrange Multiplier (LM) test, ${ }^{11}$ suggesting that the OLS model should be rejected. ${ }^{12}$ In the absence of different $p$ values associated with the $\chi^{2}$ values of the robust LM tests, ${ }^{13}$ so that, following Anselin and Rey (1991), the model with the lowest $p$-value could be chosen, the spatial lag model is adopted based on theoretical considerations. Specifically, in setting a seller's asking price and/or guiding a buyer's bidding price, realtors use comparable values which are based on neighbouring values and thus cause prices at which residences sell to be related to prices of neighbouring residential sales. The estimated coefficients for both the OLS estimation and the spatial lag regression are reported in Table 3. Heteroskedasticity is also suspected within the data given findings presented in the literature and the nature of housing data. A White test indicates that the null hypothesis of homoskedastic errors can be rejected. Accordingly, Huber-White corrected standard errors, which are reported in Table 3, are obtained for both the OLS regression and the spatial regression.

For the spatial lag model, a weight matrix is constructed. House locations are assigned geographic $x$ and $y$ coordinates using GIS. ${ }^{14}$ The relationship of errors within the spatial weight matrix is then represented as a weighted function of the inverse of the distance between observations. ${ }^{15}$ Model 2 is then estimated using a maximum likelihood spatial 
autoregressive model.

\begin{tabular}{|c|c|c|}
\hline & Model 1 - OLS & Model 2 - Spatial Lag \\
\hline AGE & $-415.75(68.66)^{\star \star \star}$ & $-400.57(67.22)^{\star * *}$ \\
\hline LOT_SIZE & $0.33(0.21)$ & $0.41(0.20)^{\star *}$ \\
\hline TLA & $19.89(2.22)^{\star \star \star}$ & $19.69(2.14)^{\star \star \star}$ \\
\hline NBR_BATH & $5846.51(2583.36)^{\star *}$ & $6124.31(2468.53)^{* *}$ \\
\hline NBR_BED & $-1245.94(1555.70)$ & $-906.20(1538.34)$ \\
\hline FIREPLACE & $6923.23(2106.20)^{\star \star \star}$ & $6707.58(2050.65)^{\star \star \star}$ \\
\hline GARAGE & $5737.40(2127.21)^{\star \star \star}$ & $6277.91(2050.98)^{\star \star \star}$ \\
\hline TWO_STOREY & $9226.00(2785.15)^{\star \star *}$ & $8858.14(2732.78)^{\star \star *}$ \\
\hline D_CBD & $-3.71(2.06)^{*}$ & $-1.48(1.95)$ \\
\hline LN_D_SITE & $8366.75(1372.23)^{\star \star \star}$ & $7004.59(1390.54)^{\star * \star}$ \\
\hline CONSTANT & $-16724.63(12407.35)$ & $-19373.46(12026.80)$ \\
\hline$R^{2}$ & 0.61 & \\
\hline Squared correlation & & 0.62 \\
\hline LM test (error) $\left(\chi^{2}, \mathrm{df}=1\right)$ & $15.50^{\star \star \star}$ & \\
\hline LM test $(\operatorname{lag})\left(\chi^{2}, \mathrm{df}=1\right)$ & $14.15^{\star \star \star}$ & \\
\hline Log likelihood & & -4347.62 \\
\hline Spatial lag $(\rho)$ & & $0.49^{\star \star \star}$ \\
\hline
\end{tabular}

Table 3. Estimated coefficients of OLS and spatial regressions. Huber-White standard 
errors in parentheses. * denotes significance at the $10 \%$ level, ${ }^{* *}$ significance at the $5 \%$ level, and ${ }^{* * *}$ significance at the $1 \%$ level.

The parameter estimate for the spatial lag $(\rho)$ is 0.49 and significant at the $1 \%$ level suggesting that the prices charged at one site are very closely related to those charged at neighbouring sites. The coefficients on age, the number of bedrooms, distance to the $\mathrm{CBD}$, distance to the Tar Ponds site, and the dummy variables for fireplace and twostorey are slightly less statistically significant with the spatial lag model, while those on the size of the property, the total living area, the number of bathrooms, the constant, and the dummy variable for garage or shed are slightly more statistically significant. One important change pertains to the distance to the CBD downtown coefficient, which is significant in the OLS regression (at the $10 \%$ level of significance) yet highly insignificant in the spatial regression. Sydney is geographically small so that few houses are more than 4 kilometres from the CBD. Further complicating the issue is the fact that the hazardous waste site is also near the city centre. Another important difference is that the size of the property is insignificant in the OLS model but significant in the spatial model at the $5 \%$ level. The magnitude of the distance to the Tar Ponds site coefficient also decreases substantially, from 8366.75 in the OLS model to 7004.59 in the spatial model. This difference leads to significant differences in the total willingness-to-pay for the community (in the order of $\$ 32.9$ million, as below shown).

Most variables have coefficients with the expected sign. The coefficient for AGE is significant in both models, and indicates that a one-year older home is expected to 
command approximately $\$ 401$ less in price. A negative price-age relationship is also detected in other studies in this literature (Kohlhase, 1991; Kiel, 1995). The number of bedrooms does not appear to have any impact on prices in either the OLS or spatial regressions. Although more bedrooms seem preferable to fewer bedrooms, living area is also accounted for, so that extra bedrooms possibly represent a decreased quality of living space given smaller rooms and more division within a home (Havlicek et al., 1971). The addition of one more square foot of living space increases the predicted house price by approximately $\$ 20$ in both regressions. These results are consistent with past works; for example, Thayer et al. (1992) determine an extra square foot of living space to be worth $\$ 29$. The addition of one more bathroom to a home increases predicted house price by approximately $\$ 6,124$. Fireplaces and garages or sheds have a relatively large impact, $\$ 6,708$ and $\$ 6,278$ respectively. A two-storey house sells for a predicted $\$ 8,858$ more than a bungalow or split-level home.

The relationship between distance and predicted price, which is the focus of this study, is significant in both models. Interpretation of the coefficient for the distance variable, $\$ 7,005$ in Model 2 (significant at the $1 \%$ level), implies that homes farther from the site are worth substantially more than identical homes closer to the site, as expected. Due to the assumed non-linearity, the magnitude of the distance premium depends on the initial location of the home. An otherwise identical home at 1.5 kilometres from the site would be worth $\$ 7,695$ more than at 0.5 kilometres, while a home 2 kilometres from the site would be worth approximately $\$ 4,855$ more than the same home at 1 kilometre from the site. A summary of the literature on this issue by Farber (1998) reports the premium 
for distance from a hazardous waste site to range between $\$ 1,875$ and $\$ 9,375$ (US 1993) per kilometre, with an average of $\$ 2,188$ (US1993) per kilometre. Adjusting these prices to Canadian 1997 dollars for comparison, the implied range is $\$ 2,855$ and $\$ 14,280$ per kilometre with an average value of $\$ 3,333$ per kilometre.

To assess the total property value impact of the Tar Ponds and Coke Ovens site on the community, each dwelling in the sample is valued, using the estimated model, at its current location and at the outermost edge of Sydney, 6 kilometres from the site (the furthest observation in the sample is 5.917 kilometres). ${ }^{16}$ The predicted change in value is averaged and multiplied by the 14,661 dwellings in Sydney (Statistics Canada, 2001) to determine the total impact of the site. ${ }^{17}$ This information is summarized in Table 4.

\begin{tabular}{|l|c|c|c|}
\hline & Coefficient & Average Change in Value & Community Change in Value \\
\hline OLS & 8366.75 & $\$ 13,787$ & $\$ 202,138,328$ \\
\hline Spatial & 7004.59 & $\$ 11,543$ & $\$ 169,228,925$ \\
\hline
\end{tabular}

Table 4. Community benefits derived from total property value impacts.

The results of this analysis imply that the total willingness-to-pay for the clean-up of the Tar Ponds and Coke Ovens site is approximately $\$ 169.2$ million. OLS estimates would provide the much larger figure of $\$ 202.14$ million. Based on the lower estimate, derived from the spatial lag model, any work leading to the cleaning up of the site for less than $\$ 169.2$ million dollars would result in a net benefit to the community. This compares 
very closely to the results of a study conducted by Kiel and Zabel (2001) which estimates the benefits of hazardous waste site clean-up to be between $\$ 72$ and $\$ 122$ million (1992) dollars (\$112.8 and \$192.7 million CDN 1997 dollars). Table 5 presents a summary of the present values of the costs of all remediation options for both the Tar Ponds and Coke Ovens, ${ }^{18}$ as detailed in Appendix $1 .{ }^{19}$

\begin{tabular}{|l|c|c|c|c|c|c|}
\hline & $\begin{array}{c}\text { Tar Ponds } \\
1\end{array}$ & 2 & 3 & 4 & 5 & 6 \\
\hline Coke Ovens 1 & 154.1 & 212.2 & 246.2 & 162.6 & 172.2 & 117.8 \\
\hline Coke Ovens 2 & 135.1 & 193.2 & 227.3 & 143.7 & 153.3 & 98.9 \\
\hline Coke Ovens 3 & 181.2 & 239.4 & 273.4 & 189.8 & 199.4 & 145.0 \\
\hline Coke Ovens 4 & 172.7 & 230.8 & 264.8 & 181.2 & 190.8 & 136.4 \\
\hline
\end{tabular}

Table 5. Matrix of present value of remediation costs, Tar Ponds and Coke Ovens areas, in millions of 1997 dollars.

Given the substantial cost variation across the various cleaning up options, varying degrees of remediation are assumed. However, in the absence of any information about the degree of remediation of each option, it is not possible to directly compare the benefits above computed based on complete remediation and the present value of the costs of each of the options. Instead, in cases where the benefits exceed the costs, the ratio of costs to benefits is computed as a conservative measure of the minimum degree of remediation necessary for the option to be viable; ${ }^{20}$ in cases where the costs exceed 
the benefits, the difference between one and the ratio of benefits to costs is computed as a speculative measure of the additional cost recovery necessary for the option to be viable. ${ }^{21}$

\begin{tabular}{|l|c|c|c|c|c|c|}
\hline & Tar Ponds & Tar Ponds & Tar Ponds & Tar Ponds & Tar Ponds & Tar Ponds \\
& 1 & 2 & 3 & 4 & 5 & 6 \\
\hline Coke Ovens 1 & 91.06 & $(20.25)$ & $(31.26)$ & 96.08 & $(1.73)$ & 69.61 \\
\hline Coke Ovens 2 & 79.83 & $(12.41)$ & $(25.55)$ & 84.91 & 90.59 & 58.44 \\
\hline Coke Ovens 3 & $(6.61)$ & $(29.31)$ & $(38.10)$ & $(10.84)$ & $(15.13)$ & 85.68 \\
\hline Coke Ovens 4 & $(2.01)$ & $(26.68)$ & $(36.09)$ & $(6.61)$ & $(11.31)$ & 80.60 \\
\hline
\end{tabular}

Table 6. Figures are in percentages. Those in brackets provide speculative measures of additional recovery for options to be viable. The remaining figures (those not in brackets) provide conservative measures of minimum remediation for options to be viable.

From the results presented in Table 6, it can then be concluded that, depending on their degree of remediation, there may be clean-up options that would result in a significant net benefit to society, despite benefits being based solely on imputed willingness-to-pay of local residents. The option recommended to government by the Joint Action Group (JAG), namely, the combination of Tar Ponds option 3 and Coke Ovens option 4, has a net cost of $\$ 95.6$ million, assuming $100 \%$ remediation; put it differently, the recommendation requires a minimum of an additional $36.09 \%$ in cost recovery from 
other benefits. Provided the clean-up combinations are feasible, Tar Ponds option 6 and Coke Ovens option 2 would require the lowest degree of remediation (58.44\%), while Tar Ponds option 4 and Coke Ovens option 1 would require the largest (96.08\%). Among cases where additional cost recovery is needed (even if complete remediation is assumed), Tar Ponds option 3 and Coke Ovens option 3 would involve the largest additional cost recovery (38.10\%), while Tar Ponds option 5 and Coke Ovens option 1 would involve the lowest (1.73\%).

While estimating benefits using a hedonic model does provide a measure of property value impacts and therefore a proxy of the willingness-to-pay of individuals, the true benefit is likely to be all the greater as a variety of other benefits are realistic but ignored in the analysis. Although it is a contentious issue, the potential for a reduction in health care costs and increased tourism may be a significant benefit of the clean-up project. The removal of the stigma of the Tar Ponds and Coke Ovens legacy may also result in intangible benefits. Lastly, but not least, future land use may yield benefits from potential enjoyment of the site.

\section{Conclusion}

The paper presents a hedonic analysis of the prices of properties in Sydney, Nova Scotia, Canada, near the Tar Ponds and Coke Ovens site, one of the most toxic hazardous waste sites in North America, to quantify the willingness-to-pay of local 
residents for a clean-up. To correct for dependence of the prices charged at one location on the prices charged at neighbouring locations, a spatial lag model is estimated. The correction amounts to a deflation of a majority of the OLS parameter estimates, including the estimate of the coefficient associated with LN_D_SITE (the natural logarithm of the distance to the hazardous waste site). In the spatial lag model, two otherwise identical houses are found to differ by $\$ 4,855$ in value if one is located at 1 kilometre from the waste site and the other at 2 kilometres; the difference decreases to $\$ 2,840$ if one house is located at 2 kilometres from the waste site and the other at 3 kilometres. In the OLS regression, the same comparisons yield $\$ 5,799$ and $\$ 3,392$, respectively.

The lower estimate of the coefficient on LN_D_SITE in the spatial lag model results in a quite significant change in the estimate of the willingness-to-pay for the cleaning up of the site. Under the assumption that the sample employed in the analysis is representative, a total willingness-to-pay is computed for the entire community based upon the sample average willingness-to-pay as measured by the estimated change in the value of each of the properties in the sample if it is to be moved to the outermost edge of Sydney. The spatial lag model provides a figure of total willingness-to-pay of $\$ 169.2$ million (in 1997 dollars), approximately $\$ 33$ million short of the figure obtained with the OLS regression (\$202.1 million in 1997 dollars). The scale of total property value impacts (or total willingness-to-pay among community residents) is substantial despite the fact that the community in question has continually high unemployment and low income levels relative to national (and provincial) averages. If property values are to 
rebound after remediation, homes closest to the site may be predicted to increase by more than $\$ 30,000$, while properties near the outer edge of Sydney may not increase by more than a few hundred dollars. Previous studies illustrate that property values typically do recover to some extent after remediation, suggesting homeowners near the site stand to benefit most from the remediation.

In the final part of the paper, notwithstanding the fact that potentially relevant benefits other than those estimated in the paper (e.g., health improvement, increased tourism) are ignored, the total willingness-to-pay is compared to the costs of the various options proposed for the cleaning up of the site. Given the high variation in costs among the options, different degrees of remediation are presumed and comparisons between costs and benefits are carried out to determine a conservative measure of the minimum degree of remediation necessary for each option to be viable (in cases where benefits exceed costs) and a speculative measure of the minimum additional cost recovery necessary for each option to be viable (in cases where costs exceed benefits). In the former cases, the measure is conservative because of the omission of other potentially significant benefits and the required degree of remediation ranges from $58.44 \%$ (Tar Ponds option 4 and Coke Ovens option 1) to 96.08\% (Tar Ponds option 6 and Coke Ovens option 2); in the latter cases, the measure is speculative because of the assumption of $100 \%$ remediation and the required additional cost recovery ranges from 1.73\% (Tar Ponds option 5 and Coke Ovens option 1) to 38.10\% (Tar Ponds option 3 and Coke Ovens option 3). The clean-up recommendations of the Joint Action Group to the government of Canada of Tar Ponds option 3 and Coke Ovens option 4 would 
require, under the assumption of complete remediation, additional benefits of $\$ 95.6$ million; put it differently, the willingness-to-pay of local residents would cover $63.91 \%$ of the clean-up costs of the recommended option.

\section{Appendix 1}

Tar Ponds Option 1: This option involves the construction of a dam at the mouth of the North Pond at Sydney Harbour. Surface water and stream flows from the Coke Ovens site would be redirected to the North Pond and Sydney Harbour. Contaminated sediment from the North Pond would be excavated and encapsulated in a confined disposal facility or berm in the location of the South Pond (which would no longer be a pond). PCB contaminated sediment from both ponds would be excavated and destroyed offsite. A sub-aqueous cap would be placed over dredged areas. The cost and term of this option is $\$ 152$ million over four years (CBCL/ENSR, 2003b).

Tar Ponds Option 2: This option involves the construction of a dam at the mouth of the North Pond at Sydney Harbour. Surface water and stream flows would be redirected to the North Pond and Sydney Harbour. Contaminated sediment from both North and South Ponds would be excavated and encapsulated at the Coke Ovens Site. PCB contaminated sediment from both ponds would be excavated and destroyed offsite. A sub-aqueous cap is to be placed over dredged areas. The cost and term of this option is \$246 million over five years (CBCL/ENSR, 2003b). 
Tar Ponds Option 3: This option involves the construction of a dam at the mouth of the North Pond at the Sydney Harbour. Surface water and stream flows would be redirected to the North Pond and Sydney Harbour. Contaminated sediment from both North and South Ponds would be excavated for treatment and possible encapsulation at the Coke Ovens Site. PCB contaminated sediment from both Ponds would be excavated and treated at the Coke Ovens Site. This option calls for the use of various treatment technologies 'inline'. A sub-aqueous cap would be placed over dredged areas. The cost and term of this option is $\$ 323.8$ million over seven years (CBCL/ENSR, 2003b).

Tar Ponds Option 4: This option involves the construction of a dam at the mouth of the North Pond at the Sydney Harbour. Surface water and stream flows would be redirected to the North Pond and Sydney Harbour. Contaminated sediment from the North and South Ponds would be excavated for removal and offsite co-burning process to destroy contaminants and produce energy. PCB contaminated sediment from both Ponds would be excavated and incinerated offsite. This option calls for the use of various processes to prepare excavated sediment for burning. A sub-aqueous cap is to be placed over dredged areas. The cost and term of this option is $\$ 220.4$ million over eleven years (CBCL/ENSR, 2003b).

Tar Ponds Option 5: This option involves the construction of a dam at the mouth of the North Pond at the Sydney Harbour. Surface water and stream flows would be redirected to the North Pond and Sydney Harbour. Contaminated sediment from both North and 
South Ponds would be excavated for incineration at the Coke Ovens Site. PCB contaminated sediment from both Ponds would be excavated for incineration at the Coke Ovens Site. Sediments with residual contamination after treatment will be encapsulated at the Coke Ovens Site. This option calls for the use of various processes to prepare excavated sediment for burning. A sub-aqueous cap is to be placed over dredged areas. The cost and term of this option is $\$ 238.9$ million over eleven years (CBCL/ENSR, 2003b).

Tar Ponds option 6: This option involves the construction of a dam at the mouth of the North Pond at the Sydney Harbour. Surface water and stream flows are to be redirected to the North Pond and Sydney Harbour. Contaminated sediment in both the North and South Ponds would be capped with the placement on an above ground cap. The cost and term of this option is $\$ 100$ million over four years (CBCL/CRA, 2003b).

Coke Ovens Option 1: This option involves the in-situ containment of most of the contaminated materials and the re-routing of surface water and other watercourses away from potential contact with contaminants. Contaminated groundwater would be treated on site. The top 0.5 metres of the site would be land farmed to remediate volatiles and any remaining portions of the site would be covered with low permeability soil to prevent surface water infiltration. Part of this option involves the construction of a containment facility to contain excavated sediment from the Tar Ponds. This option would see the installation of a down gradient vertical barrier at the west side of the Coke Ovens Site and the Coke Ovens Brook Connector to protect against potential non- 
aqueous phase liquid (NAPL) migration. The cost and term of this option is $\$ 69$ million over four years (CBCL/ENSR, 2003a).

Coke Ovens Option 2: This option involves the excavation of all contaminated material at the Coke Ovens Site, the Coke Oven Brook and Connector Brook. Contaminated material, potentially along with sediment from the Tar Ponds, would be placed into a containment facility at the Coke Ovens Site. Site surface water would be diverted and watercourses would be re-routed away from potential contact with contaminants. This option would see the installation of a down gradient vertical barrier at the west side of the Coke Ovens Site and the Coke Ovens Brook Connector to protect against potential NAPL migration. The cost and term of this option is $\$ 43.7$ million over five years (CBCL/ENSR, 2003a).

Coke Ovens Option 3: This option involves the excavation of all contaminated material at the Coke Ovens Site, Coke Oven Brook and Connector Brook. Contaminated material would be treated on site with a soil washing technology to concentrate contaminants into a slurry to be destroyed in a subsequent co-burning process. Materials with residual contamination after treatment would be contained in an onsite landfill. Site surface water and watercourses would be re-routed away from potential contact with contaminants. This option would see the installation of a down gradient vertical barrier at the west side of the Coke Ovens Site and the Coke Ovens Brook Connector to protect against potential NAPL migration. The cost and term of this option is $\$ 123$ million over seven years (CBCL/ENSR, 2003a). 
Coke Ovens Option 4: This option involves the excavation of all contaminated material at the Coke Ovens Site, Coke Oven Brook and Connector Brook. Contaminated material would be treated using a thermal desorption/pyrolysis technology to concentrate and immobilize contaminants that would be subsequently destroyed by coburning. Site surface water would be diverted and watercourses would be re-routed away from potential contact with contaminants. This option would see the installation of a down gradient vertical barrier at the west side of the Coke Ovens Site and the Coke Ovens Brook Connector to protect against potential NAPL migration. The cost and term of this option is $\$ 109$ million over seven years (CBCL/ENSR, 2003a). 


\section{References}

Adler, K., Z. Cook, A. Ferguson, M. Vickers, R. Anderson, and R. Dower, 1982. The Benefits of Regulating Hazardous Disposal: Land Values as an Estimator, U.S. Environmental Protection Agency. Washington, GPO.

Anselin, L., 1988. Spatial Econometrics: Methods and Models. Dordrecht: Kluwer Academic.

Anselin, L., A. K. Bera, R. Flora, and M. J. Yoon, 1996. "Simple Diagnostic Tests for Spatial Dependence," Regional Science and Urban Economics 26(1): 77-104. Anselin, L., and S. Hudak, 1992. "Spatial Econometrics in Practice: A Review of Software Options," Regional Science and Urban Economics 22: 509-536.

Anselin, L., and S. Rey, 1991. "Properties of Tests for Spatial Dependence in Linear Regression Models," Geographical Analysis 23: 112-131.

Basu, S., and T. G. Thibodeau, 1998. Analysis of Spatial Autocorrelation in House Prices, Journal of Real Estate Finance and Economics 17(1): 61-85.

Bell, K, and N. Bockstael, 2000. "Applying the Generalized-Moments Estimation Approach to Spatial Problems Involving Microlevel Data," Review of Economics and Statistics, 82(1): 72--82.

Brasington, D.M., and D. Hite, 2005. "Demand for Environmental Quality: A Spatial Hedonic Analysis," Regional Science and Urban Economics, 35(1): 57-82.

Can, A., 1990. "The Measurement of Neighborhood Dynamics in Urban House Prices," 
Economic Geography, 66: 254-272.

CBCL Limited and Conestoga-Rovers \& Associates (CBCL/CRA), 1999. Phase 1

Environmental Site Assessment Muggah Creek Watershed. Sydney, NS: Supply and Services Canada.

CBCL Limited and ENSR International,2003a. Remedial Action Evaluation Report (RAER). Coke Oven Site. Halifax: Nova Scotia Department of Transportation and Public Works.

CBCL Limited and ENSR International, 2003b. Remedial Action Evaluation Report (RAER). Tar Pond Site. Halifax: Nova Scotia Department of Transportation and Public Works.

Cropper, M. L., L. B. Deck, and K. E. McConnell, 1988. "On the Choice of Functional Form for Hedonic Price Functions," Review of Economics and Statistics 70(4): 668675.

Dubin, R. A., 1988. "Estimation of Regression Coefficients in the Presence of Spatially Autocorrelated Error Terms," Review of Economics and Statistics 70(3): 466-474. Englin, J., 1996. "Estimating the Amenity Value of Rainfall," Annals of Regional Science 30: $273-284$.

Farber S., 1998. "Undesirable Facilities and Property Values: A Summary of Empirical Studies," Ecological Economics 24(1): 1-14.

Gawande, K., and H. Jenkins-Smith, 2001. "Nuclear Waste Transport and Residential Property Values: Estimating the Effects of Perceived Risks," Journal of Environmental Economics and Management 42: 207-233.

Gayer, T., J. T. Hamilton, and W. K. Viscusi, 2000. "Private Values of Risk Tradeoffs at 
Superfund Sites: Housing Market Evidence on Learning about Risk," Review of Economics and Statistics 82(3): 439-451.

Harrison, D. Jr., and D. L. Rubinfeld, 1978. "Hedonic Housing Prices and the Demand for Clean Air," Journal of Environmental Economics and Management 5(1): 81-102. Havlicek, J., R. Richardson, and L. Davies, 1971. "Measuring the Impacts of Solid Waste Disposal Site Location on Property Values," American Journal of Agricultural Economics 53(5): 869.

Hunt, L.M., P. Boxall, J. Englin, and W. Haider, 2005. "Remote Tourism and Forest Management: A Spatial Hedonic Analysis," Ecological Economics 53: 101-113. Ihlanfeldt, K. R., and L. O. Taylor, 2004. "Externality Effects of Small-Scale Hazardous Waste Sites: Evidence from Urban Commercial Property Markets," Journal of Environmental Economics and Management 47(1): 117-139.

JDAC, 2002. Contaminant Loading Study for Muggah Creek, Sydney, N.S. Phases II/III Environmental Site Assessment Muggah Creek Watershed. Halifax: Nova Scotia Department of Transportation and Public Works.

Joint Action Group (JAG), 1998. Muggah Creek Watershed Joint Action Group for Environmental Clean-up Memorandum of Understanding among the Government of Canada, the Government of the Province of Nova Scotia, the Cape Breton Regional Municipality and the Joint Action Group for Environmental Clean-up Sydney: JAG. Ketkar, K., 1992. "Hazardous Waste Sites and Property Values in the State of New Jersey," Applied Economics 24(6): 647-659.

Kiel, K. A., 1995. "Measuring the Impact of the Discovery and Cleaning of Identified Hazardous Waste Sites on House Values," Land Economics 71(4): 428-435. 
Kiel, K., and J. Zabel, 2001. "Estimating the Economic Benefits of Cleaning Up Superfund Sites: The Case of Woburn, Massachusetts," Journal of Real Estate Finance and Economics 22(2/3): 163-184.

Kiel, K.A., and K.T. McClain, 1995. "House Prices during Siting Decision Stages: The Case of an Incinerator from Rumor through Operation," Journal of Environmental Economics and Management 38: 241-255.

Kohlhase, J. E., 1991. "The Impact of Toxic Waste Sites on Housing Values," Journal of Urban Economics 30(1): 1-26.

Lancaster, Kelvin J., 1966. "A New Approach to Consumer Theory," Journal of Political Economy, 74(2), 132-157.

Leggett, C.G., and N.E. Bockstael, 2000. "Evidence of the Effects of Water Quality on Residential Land Prices," Journal of Environmental Economics and Management 39: 121-144.

Mahan, B.L., S. Polosky, and R.M. Adams, 2000. "Valuing Urban Wetlands: A Property Price Approach," Land Economics 76(1): 100--113.

Mendelsohn, R., D. Hellerstein, M. Huguenin, R. Unsworth, and R. Brazee, 1992. "Measuring Hazardous Waste Damages with Panel Models," Journal of Environmental Economics and Management 22: 259-271.

Michaels, R. G., and V. K. Smith, 1990. Market Segmentation and Valuing Amenities with Hedonic Models: The Case of Hazardous Waste Sites, Journal of Urban Economics 28(2): 223-242.

Nova Scotia Department of Health and the Cape Breton District Health Authority,2001. Lead and Arsenic Biological Testing Program In Residential Areas Near the Coke 
Ovens Site Halifax: Government of Nova Scotia.

Orford, S., 1999. Valuing the Built Environment: GIS and House Price Analysis Brookfield: Ashgate Publishing Ltd.

Pace, R. K., and O. W. Gilley, 1997. "Using the Spatial Configuration of the Data to Improve Estimation," Journal of Real Estate Finance and Economics 14(3): 333-340.

Palmquist, R.B., 1991. "Hedonic Methods" in Measuring the Demand for Enviromental Quality, eds. J. B. Braden and C. D. Kolstad. Amsterdam: North-Holland.

Palmquist, R.B., (1992), "Valuing Localized Externalities," Journal of Urban Economics, 31, 59-68.

Palmquist, R.B., F.M. Roka, and T. Vukina, 1997. "Hog Operations, Environmental Effects, and Residential Property Values," Land Economics 73: 114-124.

Poor, P.J., K.J. Boyle, L.O. Taylor, and R. Bouchard, 2001. "Objective versus Subjective Measures of Water Clarity in Hedonic Property Value Models," Land Economics 77: 482-493.

Rosen, S., 1974. "Hedonic Price and Implicit Markets: Product Differentiation in Pure Competition," Journal of Political Economy 82(1): 34-55.

Smith, V. K., and W. H. Desvousges, 1986. "The Value of Avoiding a LULU: Hazardous Waste Disposal Sites," Review of Economics and Statistics 68(2): 293-299.

Thayer, M., H. Albers, and M. Rahmatian, 1992. "The Benefit of Reducing Exposure to Waste Disposal Sites: A Hedonic Housing Value Approach," Journal of Real Estate Research 7(3): 265-282. 


\section{Endnotes}

${ }^{1}$ By 1911 , the complex was producing over 800,000 tonnes of pig iron and 900,000 tonnes of crude steel, providing employment for over 6,000 workers. The plant was sold to the government of Nova Scotia in 1967, and eventually ceased operations in 2001.

${ }^{2}$ The Canadian Environmental Assessment Agency and the Nova Scotia Department of Environment and Labour finalized an agreement for a joint panel review of the proposed Sydney Tar Ponds and Coke Ovens Remediation Project in July, 2005.

${ }^{3}$ For more on functional forms and hedonic functions, see Cropper et al. (1988).

${ }^{4}$ To the east of the former steel site is the Municipal Ash and Industrial Disposal (MAID) site, to the North is the neighbourhood known as Whitney Pier, to the West are the lands currently occupied by Sydney Steel Company (SYSCO) beyond which are the Tar Ponds and the neighbourhood known as the North End, and to the south is the neighbourhood known as Ashby.

${ }^{5}$ While locally generated slag is considered to be inert and suitable for use as backfill, 
mixed metal waste within the slag continues to be a concern (CBCL/ENSR, 2003b).

${ }^{6}$ Nonetheless, in January 2002, signs with warnings of Human Health Hazard were affixed to fences every 50 metres around the site.

${ }^{7}$ Six clean-up options were proposed for the Tar Ponds site, and four options for the Coke Ovens site. These options are detailed in Appendix 1.

${ }^{8}$ Palmquist (1991) provides a summary of recent developments in both the first and second stages of the estimation.

${ }^{9}$ There are of course other neighbourhood characteristics (e.g., distance to parks and schools) that may be of relevance but are excluded because of lack of data.

${ }^{10}$ In general terms, a spatial error model is given by

$$
Y=X \beta+\varepsilon,
$$

with $\varepsilon=\lambda W \varepsilon+\mu$, where $Y$ denotes an $N \times 1$ vector of observations on the variable $Y$ (the dependent variable), $X$ denotes an $N \times k$ matrix of observations on the 
explanatory variables, $\beta$ denotes a $k \times 1$ vector of regression parameters, $\lambda$ denotes the spatial autoregressive parameter, $\mu$ denotes a vector of homoskedastic and uncorrelated errors, and $W$ denotes the matrix of spatial weights (Anselin and Hudak, 1992). A non-zero $\lambda$ coefficient indicates a spatial effect arising from mis-specification. A spatial lag model is instead given by

$$
Y=\rho W Y+X \beta+\mu,
$$

where $\rho$ denotes the spatial autoregressive parameter, $W Y$ denotes the spatially lagged depedent variable, and all the other terms are defined as above (Anselin and Hudak, 1992). A non-zero $\rho$ coefficient indicates a spatial lag effect.

${ }^{11}$ The robust LM test is recommended by Anselin et al. (1996) and Ihlanfeldt and Taylor (2004), particularly when both spatial lag autocorrelation and spatial error autocorrelation are suspected. The $\chi^{2}$ value of the robust LM test for each of the two models (lag and error) is given in Table 3 in the OLS column.

${ }^{12}$ Other measures of global spatial autocorrelation (Moran's $I$ and Geary's $c$ ) are also used, each of which leads to the rejection of the null hypothesis of no spatial autocorrelation at $1 \%$ level of significance. 
${ }^{13}$ For both the spatial error model and the spatial lag model, the $p$-value (not reported in Table 3) associated with the robust Lagrange multiplier is 0.000 .

${ }^{14}$ The distance band within which location pairs are considered neighbours (that is, spatially contiguous), and thus assigned a non-zero spatial weight, is set at 1000 meters. With a smaller band, at least one location would be left with no neighbours.

${ }^{15} \mathrm{~A}$ power of 2 for the inverse of the distance was also considered but not opted for given that (1) the robust LM test for the spatial error model does not yield a different result in terms of rejection of spatial autocorrelaiton due to mis-specification and (2) the data on distance are in meters. In relation to the second point, the matrix is constructed to ensure that (1) near properties have a much greater impact on a property's price than do far away properties and (2) all properties in the distance band have some contribution to any given property's price.

${ }^{16}$ Information about the distance between the actual location of each dwelling and the outermost edge of Sydney combined with the estimated coefficient on LN_D_SITE is used to compute changes in value. 
${ }^{17} \mathrm{In}$ the aggregation procedure, everyone is treated as being at the margin.

${ }^{18}$ The cost summary assumes that clean-up spending is distributed evenly over the course of the project. Discounting is performed using an annual rate of $10 \%$. To make the figures comparable with the benefits (which are in 1997 dollars), costs are then adjusted using the consumer price index from Statistics Canada available at http://www.statcan.ca/english/Pgdb/econ46.htm. The $10 \%$ discount rate is chosen for consistency with the social discount rate (applied to real dollars) required by the Treasury Board of Canada in benefit-cost analyses (http://www.tbssct.gc.ca/fin/sigs/revolving_funds/bcag/bca2_e.asp).

${ }^{19}$ It is possible for the various remediation options under consideration to involve environmental costs which may affect the Sydney area if the clean-up occurs on-site (e.g., burning waste) or areas beyond Sydney if the clean-up occurs off-site (e.g., removal of contaminants for destruction in other areas). Although potentially significant but, most likely, short-lived, these environmental costs may well change the relative performance of the various options based on cost considerations but would not affect individuals' willingness to pay for the cleaning up of the contaminated sites. Unfortunately, based on the available information, it is not possible to make any inference about the likely environmental cost of each option. 
${ }^{20}$ This is a conservative measure as there may be benefits other than local willingnessto-pay not accounted for in the analysis.

${ }^{21}$ The measure is speculative as it is based on the assumption of $100 \%$ remediation. This can be viewed as a minimum additional cost recovery. 


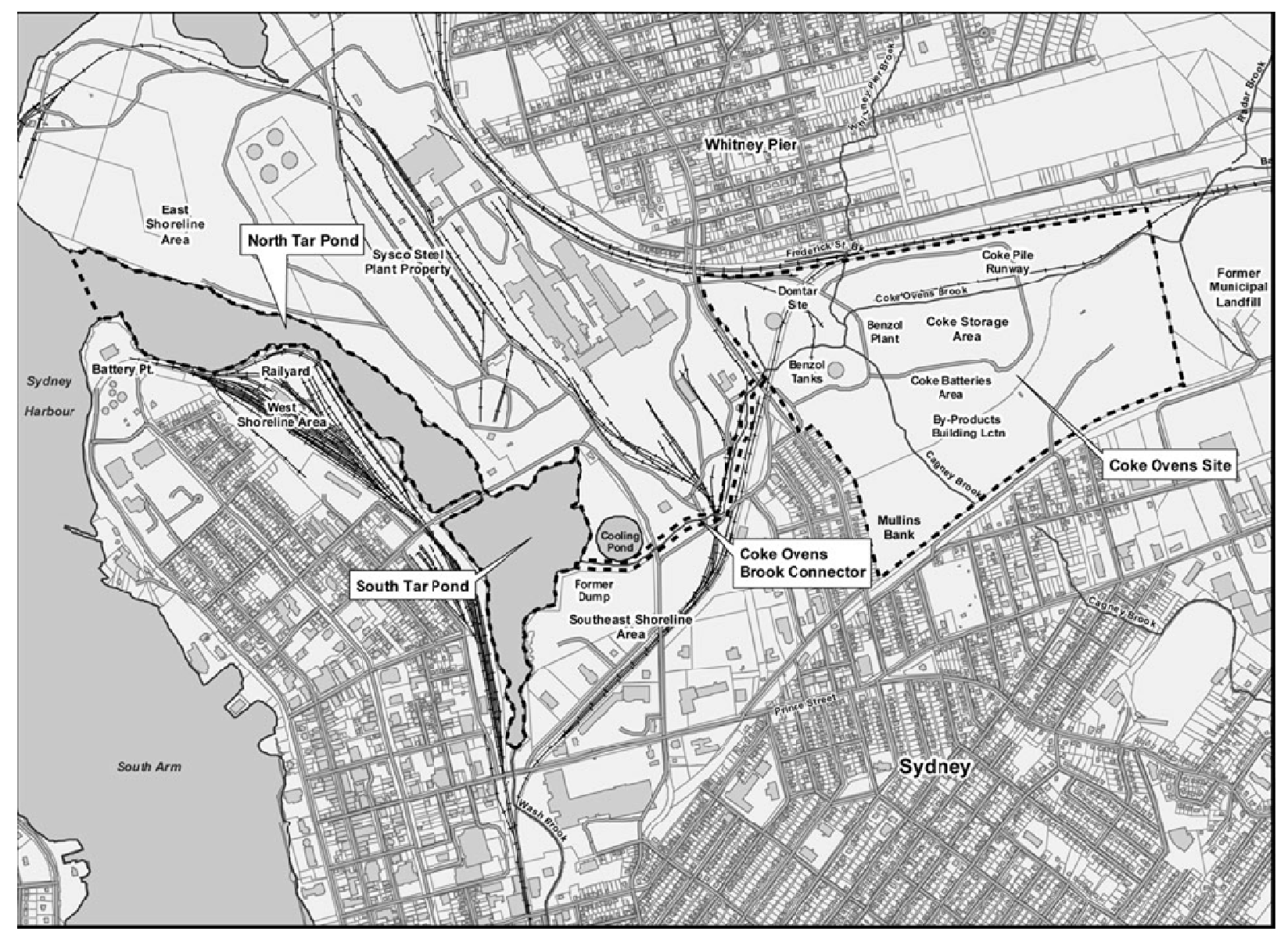

Figure 1. Map of the waste site and surrounding area. Source: Public Works and Services Canada, 2005. http://www.pwgsc.gc.ca/text/articles/2005/02/2005-02-tarponds-e.html 